\title{
Ensinando Seus Pares: a inclusão de um aluno autista nas aulas de Matemática
}

\author{
Teaching Your Peers: The inclusion of an autistic student in mathematics \\ classes
}

\author{
Roberta Caetano Fleira* \\ ORCID iD 0000-0002-6296-6834 \\ Solange Hassan Ahmad Ali Fernandes** \\ ORCID iD 0000-0003-0227-1253
}

\begin{abstract}
Resumo
Este trabalho apresenta resultados de uma pesquisa que teve como objetivo analisar as práticas matemáticas de um aluno de catorze anos de idade, com necessidades especiais decorrentes do Transtorno do Espectro Autista (TEA), incluído em uma sala de aula regular de $9^{\circ}$ ano. Neste texto, são trazidas reflexões sobre o autismo e seu histórico, além de algumas considerações teóricas que dão suporte ao estudo e são descritos os procedimentos metodológicos empregados em dez sessões individuais, duas coletivas e observações realizadas pela professora nas aulas de Matemática, nas quais se discutiu os conceitos matemáticos: Produtos Notáveis e as Equações do $2^{\circ}$ grau. As análises destacam a importância e a influência dos instrumentos mediadores (materiais e semióticos) nas práticas matemáticas do aluno e para a sua inclusão efetiva nas aulas de Matemática.
\end{abstract}

Palavras-chave: Transtorno do Espectro Autista. Ensino Fundamental. Mediação. Práticas Matemáticas.

\begin{abstract}
This project demonstrates the result of a research, which aimed at analysing the mathematics practices of a 14 year-old student, with special needs due to the Autism Spectrum Disorder (ASD), included in a ninth grade regular classroom. In this text, we bring reflections about autism and its history, in addition to some theoretical considerations that give support to the study and the methodological procedures applied in ten individual sittings, two collective ones and the observations made by the teacher in the mathematics classes, in which the mathematics concept, Notable Products and Quadratic equations, were discussed. The analyses highlight the importance and the influence of the mediating instruments (materials and semiotics) in the student's mathematical practices and for their effective inclusion in Mathematics classes.
\end{abstract}

Keywords: Autistic Spectrum Disorder. Elementary School. Mediation. Mathematical Practices.

\section{Introdução}

\footnotetext{
* Doutoranda em Educação Matemática no Programa de Pós-Graduação da Universidade Anhanguera de São Paulo (UNIAN), São Paulo, S.P, Brasil. Endereço para correspondencia: Avenida Raimundo Pereira de Magalhães, $\mathrm{n}^{\circ}$ 3.305, $1^{\circ}$ andar, Jardim Íris, São Paulo, SP, Brasil, CEP: 05145-200. E-mail: robertafleira@ hotmail.com.

** Doutora em Educação Matemática pela Pontifícia Universidade Católica de São Paulo (PUCSP). Professora do Programa de Pós-Graduação da Universidade Anhanguera de São Paulo (UNIAN), São Paulo, S.P, Brasil. Endereço para correspondencia: Avenida Raimundo Pereira de Magalhães, $\mathrm{n}^{\circ} 3.305,1^{\circ}$ andar, Jardim Íris, São Paulo, SP, Brasil, CEP: 05145-200. E-mail: solangehf@gmail.com.
} 
Neste artigo, são apresentados alguns resultados oriundos de uma pesquisa, na qual consideramos as práticas matemáticas ${ }^{1}$ de um estudante, com 14 anos de idade, que denominamos $\mathrm{Caio}^{2}$. Matriculado no $9^{\circ}$ ano do Ensino Fundamental, de uma escola particular da cidade de Guarulhos (São Paulo), Caio tem Transtorno do Espectro do Autismo (TEA).

Os episódios relatados, neste texto, são provenientes de uma sequência de intervenções realizadas com Caio, no contraturno e nas aulas de Matemática, que foram realizadas pela professora, que também é a pesquisadora. Nosso propósito é desencadear reflexões acerca da importância da interação social no processo de aprendizagem e para a inclusão de pessoas com autismo.

A proposta envolveu a utilização de diferentes recursos pedagógicos, que tiveram a finalidade de apresentar ao estudante os conteúdos de Produtos Notáveis e de Equações do $2^{\circ}$ grau. Esses conteúdos, em um momento posterior, foram estudados em sala de aula e, dessa maneira, essa antecipação serviu para que ele pudesse acompanhar a turma.

\section{A trajetória de estudo}

O primeiro passo foi conhecer detalhadamente o TEA e o que oferecia a literatura a respeito da inclusão de pessoas com autismo no sistema educacional regular. Nosso propósito foi compreender quem era Caio e encontrarmos o ponto de partida do estudo, a fim de estabelecer possibilidades de intervenções adequadas para a aprendizagem dele.

Como Caio apresentava laudo e as características do TEA, como o isolamento, os problemas de relacionamento dentro do ambiente escolar, entre outros, desde o início, buscamos ampliar o nosso olhar a respeito das pessoas com autismo (SILVA; GAIATO; REVELES, 2012). O planejamento deste estudo partiu do princípio de que o aluno tinha potencial para aprender e, posteriormente, tornar-se independente em suas práticas escolares, de modo a ser incluído no sistema educacional de ensino e ser capaz de realizar tarefas de modo autônomo.

Na literatura, deparamo-nos com autores como Kanner (1943), Sacks (2006) e Asperger (1991) que observaram a capacidade cognitiva em pessoas com autismo e destacaram a dificuldade de interação social como uma de suas características. Na perspectiva dos autores mencionados, identificamos que as pessoas com autismo apresentam algumas semelhanças

\footnotetext{
${ }^{1}$ Neste texto, usamos a expressão "práticas matemáticas" ao nos referirmos a ações intencionais, realizadas por um ou mais atores envolvidos em uma situação instrucional, sobre um cenário constituído para oferecer acesso à conteúdos matemáticos.

${ }^{2}$ Os responsáveis pelo aluno assinaram o TCLE, no qual concordaram e autorizaram a sua participação e a reprodução de imagens do trabalho realizado. Para manter o anonimato, usamos um nome fictício.
} 
entre si, referentes à dificuldade de interação com outras pessoas, de comunicação e de resistência à mudança de rotina. Deparamo-nos, também, com pesquisas que relatam que um método ideal para o tratamento das pessoas com TEA não existe, pois cada pessoa com autismo possui características próprias.

No entanto, alguns estudos como os de Bosa e Camargo (2008), Silva, Gaiato e Reveles, (2012) e Smith (2008) acreditam na educação para ajudar o desenvolvimento social e cognitivo desse público alvo da educação especial, mostrando que, mesmo com suas características próprias, pode desenvolver-se e tornar-se independente, a partir do convívio com seus pares, perspectiva esta com a qual concordamos. Nesse sentido, o professor pode organizar o cenário de aprendizagem com o intuito de aproveitar as habilidades do aluno com TEA e, ao mesmo tempo, de todos os seus alunos.

Alguns dos episódios, apresentados neste artigo, foram extraídos de procedimentos empíricos desenvolvidos em um ambiente pedagógico, que denominamos cenários inclusivos para a aprendizagem matemática. Esses cenários são constituídos por tarefas e ferramentas escolhidas e disponibilizadas de forma intencional, a fim de estimular as interações entre os diferentes atores que tomam parte da cena. Os elementos de cena são escolhidos e planejados para apresentar as representações dos objetos matemáticos, respeitando as particularidades sensoriais e cognitivas de cada aprendiz (FERNANDES; HEALY, 2017).

Buscamos apoio nas reflexões teóricas de Vygotsky, principalmente em seus trabalhos relacionados ao conceito de mediação por instrumentos e signos, e suas implicações nos processos educacionais que envolvem o público alvo da educação especial.

Na denominação Transtorno do Espectro Autista, o termo "espectro" é fundamental, pois ele denota as particularidades das pessoas com autismo, principalmente aquelas relacionadas à dificuldade de falar e de se relacionar. Cada autista, assim como as pessoas com outras limitações sensoriais ou cognitivas, possui características próprias e únicas (SMITH, 2008).

Ao refletirmos sobre os estudos de Vygotsky a respeito da ciência denominada por ele "Defectologia", encontramos semelhanças entre as características apontadas pelo autor para aqueles que ele denominou "meninos de difícil educabilidade" e as características daqueles que, atualmente, identificamos como pessoas com autismo. $\mathrm{O}$ autor considerou a diversidade e a individualidade com foco na educação, analisando o desenvolvimento desses meninos sempre de maneira qualitativa, com visão otimista em relação às possibilidades de desenvolvimento

\footnotetext{
${ }^{3}$ Termo usado por Vygotsky para denominar a ciência que estudava os processos de desenvolvimento em crianças pertencentes ao público alvo da educação especial (VEER; VALSINER, 1996).
} 
apresentadas por eles, o que consistiu uma nova forma de abordá-las (VYGOTSKY, 1997).

Iniciamos o trabalho com Caio em sessões de atendimento individual, respeitando o tempo do aprendiz. Essas sessões ocorreram no contraturno das aulas, sempre planejadas com antecedência. Após cada sessão, o desempenho e o envolvimento de Caio com a tarefa era avaliado para que a sessão seguinte fosse planejada. As atividades, aqui relatadas, mostram situações de aprendizagem envolvendo Produtos Notáveis e as Equações do $2^{\circ}$ grau. A proposta envolveu a utilização de diferentes recursos pedagógicos, com o propósito de apresentar ao estudante o mesmo conteúdo estudado em sala de aula, de maneira que ele pudesse acompanhar a turma. Todas as sessões foram gravadas em vídeo e o material produzido por Caio foi arquivado para compor os instrumentos de análises.

\section{0 início do estudo}

O que nos motivava, no início das intervenções, era criar meios para que Caio pudesse acompanhar a turma no estudo dos Produtos Notáveis, conteúdo que seria ensinado em algumas semanas. No entanto, foi necessário, primeiramente, investir na aproximação com o aprendiz. A professora/pesquisadora iniciou a observação e o registro do que acontecia em cada aula em um diário. A primeira constatação foi que o estudante não tinha conhecimento sobre Potências e Raízes, conceitos importantes para a realização de tarefas envolvendo Produtos Notáveis.

Contudo, ao iniciarmos as atividades relacionadas ao assunto Potências, constatamos que o aluno não sabia tabuada e não tinha ideia de como calcular, fosse manualmente ou usando uma calculadora. Durante as observações nas aulas de Matemática, o estudante demonstrou interesse por atividades que apresentavam aspectos de representação geométrica, denominadas por ele de "exercício com desenho".

\subsection{O primeiro encontro e as Potências}

O primeiro encontro foi marcado pelo fator ansiedade, tanto para a pesquisadora quanto para Caio. O aluno não queria sair da rotina para frequentar a escola no contraturno ${ }^{4}$ e muito menos para assistir a aula de Matemática, disciplina pela qual ele não demonstrava interesse e na qual apresentava dificuldade de concentração durante as aulas.

Caio tinha dificuldades para resolver as atividades do material didático em sala de aula,

\footnotetext{
${ }^{4}$ Caio não frequentava Atendimento Educacional Especializado (AEE) na escola ou em outro centro especializado.
} 
tanto sozinho quanto com o auxílio da professora, devido a diversos fatores, entre eles estão: o curto período da aula, a dificuldade de concentração, a falta de domínio da tabuada de multiplicação e das outras operações fundamentais e, principalmente, por ele não acreditar que tinha potencial para realizar tal ação. Nesse contexto, acreditamos que poderíamos estruturar atividades inspiradas na perspectiva vygotskiana, nas quais a professora e as ferramentas materiais poderiam mediar o processo de aprendizagem, sempre tomando por pressuposto o potencial do aprendiz.

A primeira proposta foi estruturada com o objetivo de Caio conseguir calcular sozinho alguma das potências propostas no material didático adotado pela escola como $7^{2}, 3^{4}, 2^{-4}, 10^{3}$, por exemplo. Pensou-se em utilizar cubos de um centímetro de aresta como unidade de área, apesar de ser uma figura de três dimensões, para que o aluno pudesse, em um primeiro momento, visualizar o que estava calculando, de modo a aproveitar sua preferência por representações geométricas.

A sessão começou com uma conversa informal a respeito das potências com expoente dois. A proposta inicial era explorar a representação geométrica dessas potências. A pesquisadora pediu que Caio desenhasse um quadrado, e ele produziu um retângulo. Ao ser questionado se realmente a figura desenhada era um quadrado, o aluno desenhou uma nova figura e, desta vez, representou um quadrado e afirmou que "tudo era reto, então era tudo quadrado" (Gravação de vídeo, 07/05/14). Ao ser questionado a respeito das diferenças entre as duas figuras geométricas, ele apontou para o quadrado e disse que era "tudo igual" (Gravação de vídeo, 07/05/14), o que indica que o aprendiz sabia que o quadrado tem as medidas dos lados e dos ângulos iguais.

O nosso objetivo era fazer com que Caio compreendesse primeiramente as potências com expoente dois, para depois introduzir potências de outros expoentes. A pesquisadora introduziu os cubos na atividade, deixando o aprendiz manusear as peças.

Foi solicitado que o aluno representasse quadrados com as peças, mas ele não executou a tarefa, parou, soltou o lápis e ficou olhando nos olhos da pesquisadora sem dizer uma palavra; aliás, essa cena repetiu-se durante todo o estudo, sempre que Caio não conseguia mais seguir sozinho na realização de uma tarefa. A pesquisadora passou a interagir com ele e montou quadrados de lado $1 \mathrm{~cm}$ e $2 \mathrm{~cm}$, enquanto o aluno a observava atentamente. Em seguida, ela solicitou que Caio montasse quadrados com lados de $3 \mathrm{~cm}, 4 \mathrm{~cm}$ e $5 \mathrm{~cm}$, respectivamente, conforme mostra a Figura 1, apresentada a seguir. Na tarefa seguinte, o aluno contou o número de peças contidas em cada quadrado e anotou abaixo de cada figura. 


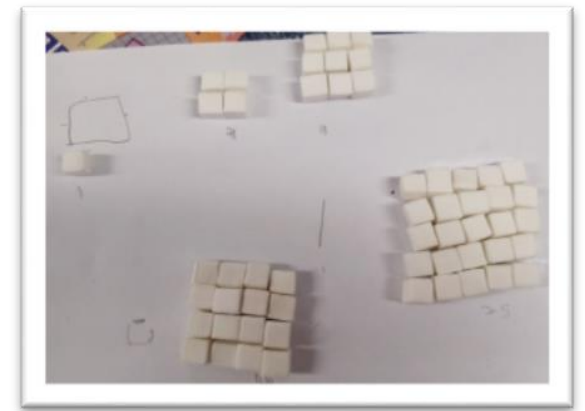

Figura 1 - Quadrados formados com os cubos Fonte: Arquivo do grupo de pesquisa (2014).

Caio ouviu a explicação da pesquisadora para o cálculo de Potências com expoente dois. Por exemplo, um ao quadrado é um multiplicado por um, e geometricamente formado por um quadrado de lado um; dois ao quadrado é dois multiplicado por dois, que é geometricamente formado por um quadrado de lado dois e assim por diante. Durante as explicações, foi possível perceber que o aluno identificava a notação utilizada para potência: $\mathrm{x}^{\mathrm{n}}$ (xis elevado a ene) e lia em voz alta cada uma das situações que foram propostas, dizendo que já havia aprendido em sala e pôde ler, por exemplo, "dois elevado à terceira potência, três elevado à quinta potência, cinco elevado à quarta potência” (Gravação de vídeo, 07/05/14). A pesquisadora questionou Caio sobre o que viria a ser potência e ele disse que não sabia o significado e nem como calcular.

No planejamento da atividade, pensou-se na calculadora como instrumento que nos auxiliaria na resolução das potências, pois, como mencionado anteriormente, o aprendiz havia demonstrado não saber calcular o produto entre dois números. Seguindo esse raciocínio, a pesquisadora falou sobre as teclas da calculadora relacionadas aos sinais de mais $(+)$, menos (), vezes (x) e dividir (/) e solicitou que Caio resolvesse algumas operações. Ele preocupava-se com o fato de que, na escola, não era permitido o uso da calculadora, mas a pesquisadora o tranquilizou dizendo que seria uma exceção, pois esta habilidade com a calculadora não poderia ser simplesmente descartada, e sim aproveitada para ser utilizada nas situações que ele julgasse necessárias.

O próximo passo consistiu em utilizar a calculadora para verificar o valor das potências determinadas com os cubos. Cabe aqui destacar que Caio utilizava uma calculadora que permitia cálculos usando as operações fundamentais $(+,-, \mathrm{x}$ e $\div)$ e porcentagem $(\%)$. O exercício pedia que calculasse o valor de $2^{2}$; a pesquisadora solicitou que Caio digitasse o valor na calculadora e o aluno colocou 2 × 2 (dois vezes dois) e foi dizendo que era quatro. O aprendiz realizou o mesmo procedimento para o número três, quatro e cinco.

A pesquisadora pediu que Caio observasse o que havia em comum entre o valor encontrado na calculadora e o que ele havia anotado anteriormente em relação ao total de cubos 
que formavam cada quadrado. Quando o aprendiz percebeu que o resultado da calculadora e das figuras era o mesmo, entusiasmou-se e disse que só confiava na calculadora, pois, se era mais fácil, não havia a necessidade de querer aprender de outra maneira. Ele rejeitou, então, o uso do material e seguiu realizando as anotações no papel e utilizando a calculadora para obter o resultado.

A sessão foi planejada de acordo com as peculiaridades do aprendiz. Desse modo, preparamos o ambiente adequadamente e todas as etapas do atendimento foram explicadas antecipadamente ao aluno para evitar que ele se sentisse ansioso. Orientadas pela perspectiva vygotskiana (1997), se apostou no processo ativo da mediação entre o aprendiz, os materiais e a pesquisadora, com o objetivo de desenvolver práticas matemáticas e, consequentemente, fornecer-lhe instrumentos para que ele pudesse realizar as tarefas de modo independente.

Nosso propósito era que Caio desenvolvesse estratégias para calcular potências, o que lhe permitiria realizar as mesmas atividades que seus colegas realizavam durante as aulas. Nesse processo, o uso do recurso tecnológico (a calculadora), juntamente com os cubos e com as intervenções da pesquisadora, serviu como instrumento de mediação e foi fundamental para que o aprendiz realizasse as atividades.

No início do estudo com potências, a pesquisadora apresentou a Caio exemplos nos quais as potências foram representadas por meio de multiplicações sucessivas para, depois, determinar o resultado. A princípio, Caio orientou-se por esse procedimento, conforme mostra a Figura 2. Depois, ele deixou de utilizar por conta própria o passo a passo e preferiu anotar somente o resultado obtido em cada caso, como pode ser observado na Figura 3.

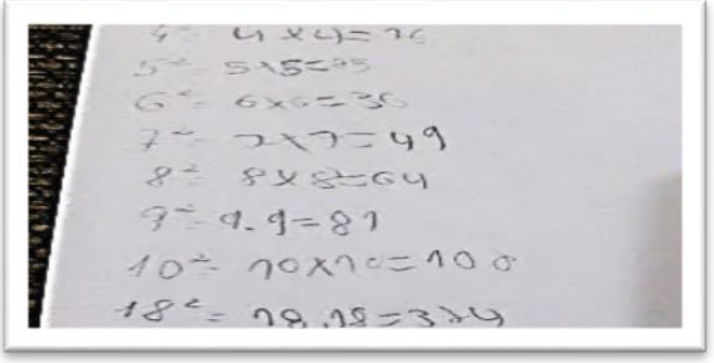

Figura 2 - Início das anotações de Caio para o cálculo de potências

Fonte: Arquivo do grupo de pesquisa (2014)

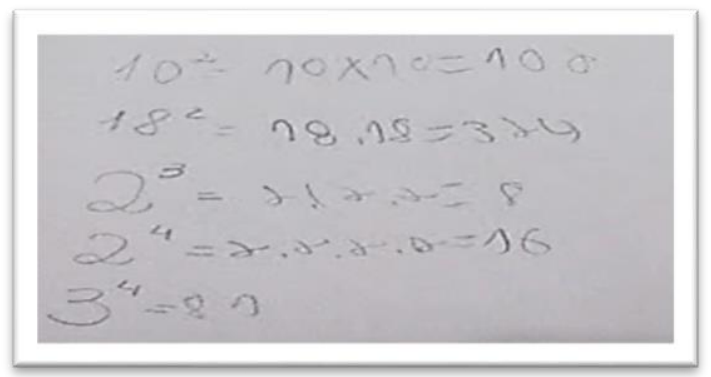

Figura 3 - Anotações do resultado obtido em cada caso

Fonte: Arquivo do grupo de pesquisa (2014)

Ao analisarmos os procedimentos de Caio, inicialmente imitando a forma de solucionar os exercícios da pesquisadora e, posteriormente, adotando uma maneira diferente para resolver as potências, verificamos que o ato de imitar não era um ato mecânico, ao contrário, esta ação foi fundamental para o seu desenvolvimento, como afirmava Vygotsky. Nessa linha de raciocínio, Oliveira (2009) afirma que se trata da reconstrução individual a partir de 
observações, uma cópia com algo novo, com a utilização de recursos próprios, individuais e legítimos para promover o próprio desenvolvimento.

$\mathrm{Na}$ sala de aula, a professora autorizou o uso da calculadora, o que deixou Caio entusiasmado. Com ela, ele conseguiu realizar alguns dos exercícios propostos no material didático, acompanhando os seus colegas. As aulas da semana seguinte tratariam do conceito matemático Produtos Notáveis.

\subsection{Encontrando os Produtos Notáveis}

As atividades envolvendo os Produtos Notáveis foram planejadas com o auxílio do Material Produtos Notáveis (Figura 4), confeccionado por Lúcia Virgínia Mamcasz Viginheski (2013), como produto final do seu trabalho de Mestrado Profissionalizante que explora a representação geométrica desse construto. Um aspecto que nos influenciou na escolha dessa ferramenta foi a possibilidade de calcular produtos notáveis usando uma representação geométrica, característica que favoreceu a aprendizagem do aluno que, como mencionado, tinha habilidade para realizar atividades por meio dessa representação.

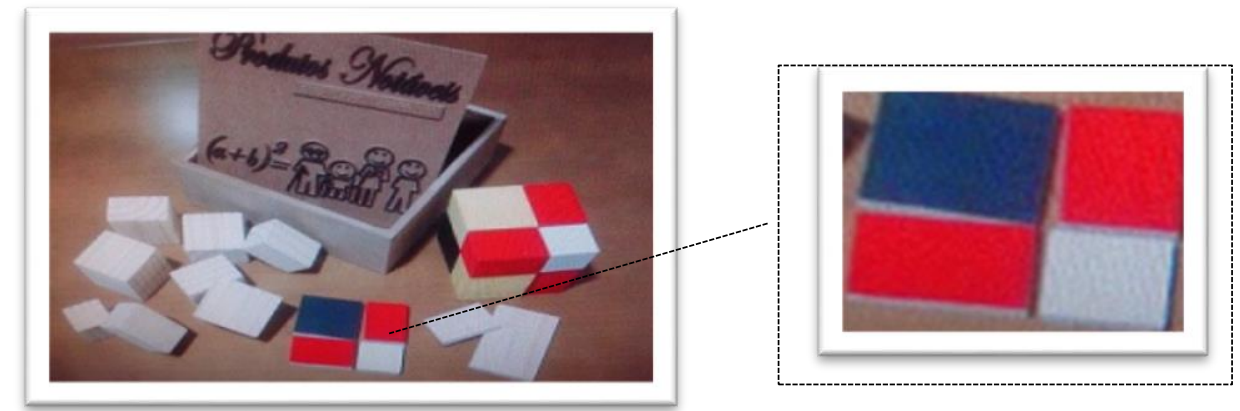

Figura 4 - Material Produtos Notáveis e detalhe da imagem Fonte: Arquivo do grupo de pesquisa (2014).

O tópico em questão contou com quatro sessões individuais e observações realizadas pela professora nas aulas coletivas sobre o conceito matemático Produtos Notáveis. O primeiro contato com o Material ocorreu com o objetivo de o aluno montar quadrados com as quatro peças (um quadrado maior, um menor e dois retângulos idênticos - conforme detalhe da Figura 4) e familiarizar-se com tal ferramenta.

A conversa com o estudante iniciou-se pelas características necessárias para que uma figura seja considerada um quadrado, assunto que havia sido explorado na sessão anterior. A pesquisadora pediu que Caio desenhasse um quadrado e, em seguida, descrevesse com palavras as características da figura. Ele desenhou, mas não disse nada.

O próximo passo consistiu em o aluno localizar, dentre as peças do Material, quais 
formariam o quadrado. Ele desenhou e dividiu um quadrado no caderno para representar as peças do Material. A pesquisadora propôs a resolução de um dos exercícios do material didático: $(\mathrm{x}+1)^{2}$, em seguida, nomeou oralmente a medida do lado do quadrado maior pela letra $x$ e a medida do lado do quadrado menor pelo número 1 e, consequentemente, os dois retângulos apresentavam dimensões 1 e $x$ (Figura 5).

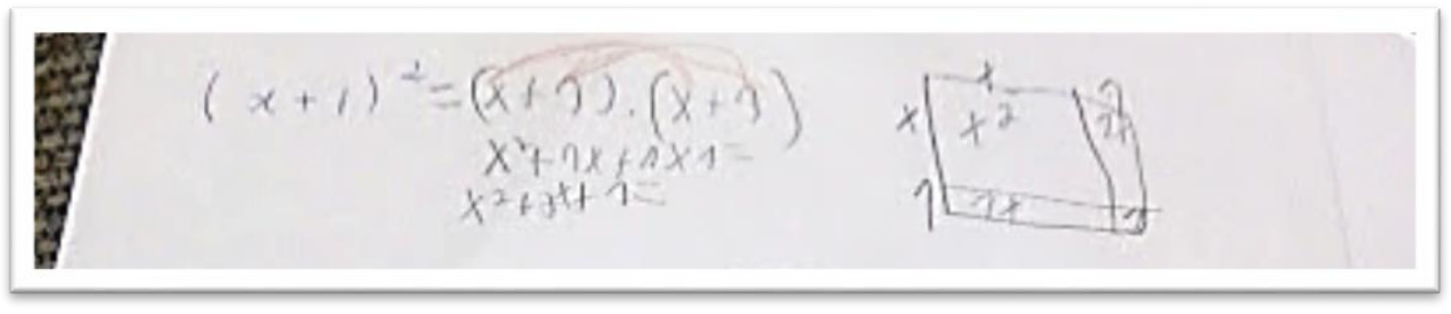

Figura 5 - Resolução de Caio

Fonte: Arquivo do grupo de pesquisa (2014).

$\mathrm{Na}$ aula seguinte, a professora levou o Material para a turma toda conhecer, o apresentou e, em seguida, propôs a resolução de exercícios da apostila envolvendo o desenvolvimento geométrico e algébrico de potências, como: $(m+7)^{2}$ e $(w-5)^{2}$. Caio participou da aula com entusiasmo, demonstrou conhecimento do assunto, respondendo às questões propostas pela professora durante a explicação para a turma toda. Essa ação causou olhar de espanto em alguns colegas e de admiração em outros, já que ele nunca participava das aulas.

Nesse episódio, os colegas de classe de Caio estavam sendo incluídos em um cenário inclusivo para a aprendizagem matemática que ele conhecia, no qual todos estavam realizando as mesmas tarefas e usando a mesma ferramenta. A partir desse episódio, o aluno começou a acompanhar e a participar das aulas de Matemática, fazendo, de acordo com seu ritmo, as tarefas do material didático. Ele pegava a calculadora e realizava as operações necessárias.

Nos três encontros individuais seguintes, foram trabalhados Produtos Notáveis com o Material (Figura 5), mesmo conceito que estava sendo trabalhado em sala de aula. Um dos exemplos trabalhados com Caio foi $(\mathrm{m}+7)^{2}$ (Figura 6).

O primeiro passo constituiu na montagem com o Material de um quadrado contendo as quatro peças, denominando a medida do lado do quadrado maior $m$, a do quadrado menor $7 \mathrm{e}$ os retângulos com dimensões $m$ e 7. Posteriormente, a pesquisadora pediu que Caio desenhasse o quadrado em seu caderno, nomeasse as dimensões das peças e, por fim, anotasse dentro de cada figura o valor da devida área. Concluindo a tarefa, Caio utilizou a propriedade distributiva, como havia sido trabalhado na sala de aula. Vale ressaltar que, para calcular $7 \mathrm{~m}+7 \mathrm{~m}$, ele necessitou utilizar a calculadora. O mesmo aconteceu para encontrar o valor de $7^{2}$. 


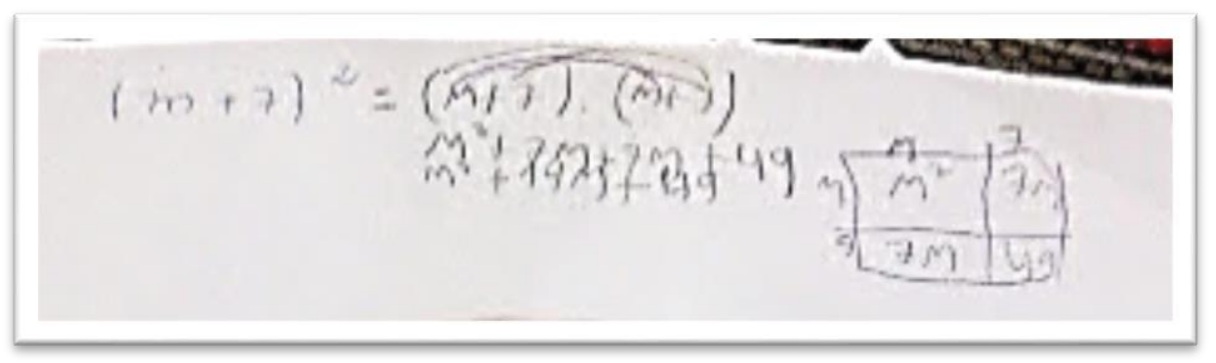

Figura 6 - Exercício realizado por Caio

Fonte: Arquivo do grupo de pesquisa (2014).

Conforme Caio resolvia os exercícios, com a mediação da pesquisadora e do Material, ele percebeu que em todos os casos tínhamos um quadrado maior, outro menor e dois retângulos idênticos. A partir do terceiro atendimento individual, a pesquisadora observou que Caio não utilizava mais o Material em todos os exercícios. Porém, desenhava o quadrado, ou seja, a representação do Material. No decorrer das atividades, o aluno deixou de utilizar o Material concreto, inclusive na sala de aula.

Para Vygotsky, a inclusão de signos na percepção temporal não leva a um simples alongamento da operação no tempo; mais do que isso, cria as condições para o desenvolvimento de um sistema único que inclui elementos efetivos do passado, do presente e do futuro (VYGOTSKY, 1998b). Com esse olhar, podemos considerar que as intervenções da pesquisadora e o uso do Material - elementos efetivos do passado - se fizeram presentes em uma nova situação e tornaram-se signos que poderão oferecer possibilidades cognitivas futuras, que contribuirão para o desenvolvimento dos aspectos educacionais de Caio.

O aluno não apresentou dificuldade para realizar exercícios com letras e números, tais como $(x+2)^{2}$, só letras como $(a+b)^{2}$, ou até mesmo números em forma de fração (Figura 7). A pesquisadora observou que, ao solicitar a Caio a realização do exercício, por exemplo, $(2 \mathrm{a}+\mathrm{b})^{2}$, primeiramente o aluno desenhava um quadrado maior e o dividia em quatro partes, conforme mostra a Figura 7; em seguida, ele preenchia as medidas, referentes às dimensões de cada quadrilátero, depois multiplicava as medidas para determinar a área e colocava o resultado obtido no centro de cada figura. Feito esse processo, o aluno voltava ao procedimento algébrico, como no exemplo citado, $(2 a+b)^{2}$, escrevia o produto, $(2 a+b) .(2 a+b)$, resolvia as multiplicações demarcadas pelos arcos com o auxílio da calculadora quando necessário e, para obter o resultado final, ele voltava ao desenho. Podemos observar que, ao multiplicar $2 a \times 2 a$, Caio anotou $4+a^{2}$, porém, na outra linha, ele anotou $4 a^{2}$, usando a área do quadrado maior na composição da figura. 


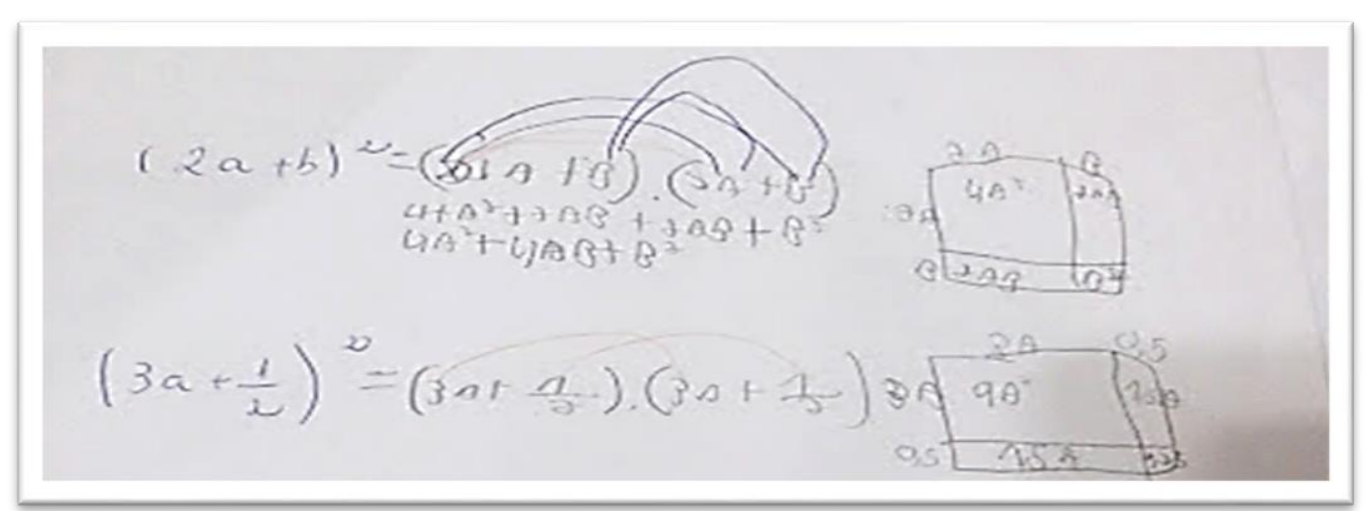

Figura 7 - Exercícios resolvidos por Caio

Fonte: Arquivo do grupo de pesquisa (2014).

A estratégia associada à representação geométrica dos Produtos Notáveis foi bem compreendida pelo aluno. Ele demonstrou entusiasmo ao efetuar o quadrado da soma e o quadrado da diferença de dois termos, para os quais representava os retângulos retirados, no caderno, ou seja, negativos, hachurados. Ele realizava esse procedimento com segurança, sem ficar aguardando a confirmação para seguir com o próximo passo. Por exemplo, para representar $(w-5)^{2}$, o aluno utilizou um quadrado grande com área $w^{2}$, um quadrado pequeno com área 25 e dois retângulos de lados 5 e $w$, com área $5 w$, cada um, que, no caso, eram negativos (hachurados) (Figura 8). E a solução deste produto, $w^{2}-10 w+25$, o aluno anotou embaixo do quadrado desenhado.

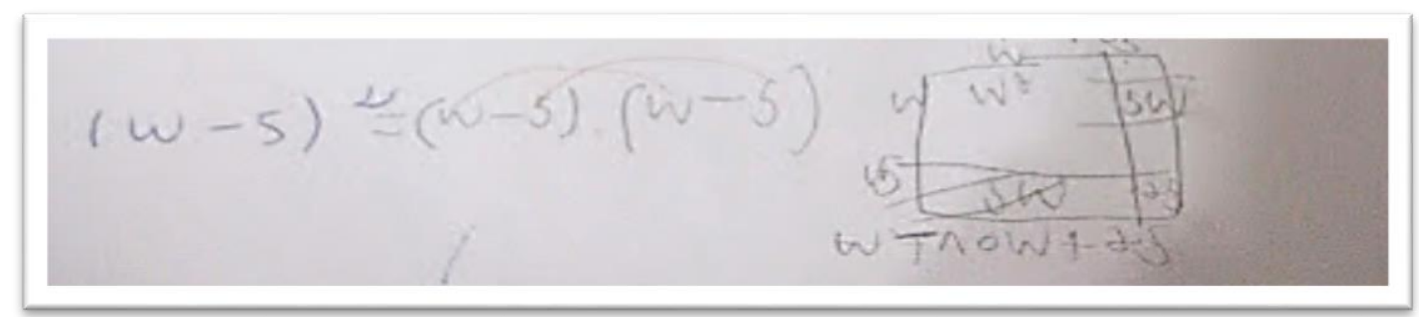

Figura 8 - Solução de Caio para $(\mathrm{w}-5)^{2}$

Fonte: Arquivo do grupo de pesquisa (2014).

Com o auxílio da calculadora, o aluno não encontrou dificuldade com números na forma decimal, como mostra a Figura 9. Para fatorar $(t-0,5)^{2}$, ele desenhou o quadrado e o subdividiu em quatro partes; sem o auxílio do Material, preencheu as laterais com as dimensões das figuras e dentro de cada uma anotou a área calculada, por meio da multiplicação das dimensões e, por último, anotou embaixo da figura o valor do produto final (Figura 9). 


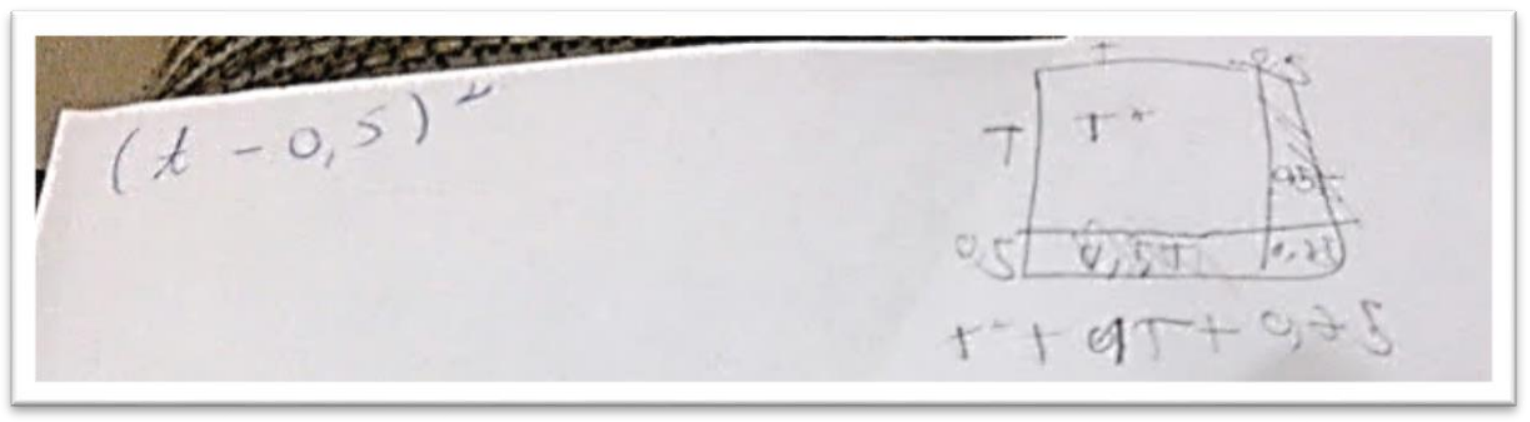

Figura 9 - Solução de Caio para $(\mathrm{t}-0,5) 2$

Fonte: Arquivo do grupo de pesquisa (2014).

Vale ressaltar que o aluno realizou sozinho e em silêncio o exercício, sem lançar um só olhar para a pesquisadora, que observava atentamente cada uma de suas ações. Ao realizar o cálculo da área do quadrado de lado $t$, o aluno anotou rapidamente $t^{2}$. Ao calcular as áreas dos retângulos de dimensões 0,5 e $t$, o aluno olhou para a calculadora, para o papel, para a calculadora novamente, como se estivesse procurando algo, até que pintou os dois retângulos e anotou $0,5 t$ em cada um e, para calcular a área do quadrado de lado 0,5 , Caio usou a calculadora.

Após as sessões individuais e as aulas em classe, Caio foi capaz de calcular e dizer, por exemplo, algebricamente que: $a$ multiplicado por $a$, multiplicado por $a$ é $a$ ao cubo, e que $a$ mais $a$ mais $a$ é $3 a$, mas não conseguia somar, por exemplo, 2ab e $2 \mathrm{ab}$ sem o uso da calculadora (somava na calculadora $2+2$ e acrescentava a parte literal).

Considerando que o objetivo da atividade, apresentada neste tópico, era calcular Produtos Notáveis usando a representação geométrica, numa tentativa de incluir Caio nas atividades propostas em sala e torná-lo participativo e confiante em seu potencial para aprender, ele foi plenamente atingido. Para Vygotsky, o uso de instrumentos e signos desenvolve formas e funções psicológicas novas que, segundo a visão do autor, possibilitam o desenvolvimento das habilidades relacionadas ao controle e à direção do próprio comportamento da criança (VYGOTSKY, 1998b).

De posse desse conhecimento matemático, o aluno relatou perceber que existem "coisas", como ele mesmo diz, que "dão pra resolver na apostila” (Gravação de vídeo, 13/08/14). Destacamos que o apoio da calculadora foi fundamental e trouxe segurança. De acordo com Vygotsky, que definiu o processo educacional como "processo de reformas biológicas de comportamento" (apud VEER; VALSINER, 1997, p. 66), entendemos que nossas ações foram fundamentais para as primeiras mudanças comportamentais de Caio. Antes das sessões, o aluno não realizava quase nenhuma atividade nas aulas de Matemática, seu caderno estava totalmente em branco, dormia muito durante as aulas, faltava com frequência, era quieto e não se importava com sua aparência. 
Acreditamos que o uso da calculadora e da ferramenta material favoreceu a interação entre professora-aluno, que antes era praticamente inexistente. Além disso, permitiu a mediação dos conceitos matemáticos descritos anteriormente, ajudando-nos a obter sucesso nas ações que foram realizadas durante pouco tempo.

O planejamento desse estudo partiu do princípio de que o aluno poderia desenvolver-se e avançar para, posteriormente, tornar-se independente em suas práticas escolares. Diante das considerações expostas até o momento, traçamos ações que respeitaram as peculiaridades do aprendiz, de modo que dessem acesso a conhecimentos matemáticos envolvendo as equações do segundo grau, pois seria o próximo conceito a ser ensinado em sala de aula. Para tanto, contamos com a prática da mediação com ferramenta material e semiótica.

\subsection{Equações do $2^{\circ}$ grau - mediação semiótica}

O objetivo das atividades era que Caio conseguisse aprender um método para resolver, de modo autônomo, as Equações do $2^{\circ}$ grau, propostas nas aulas de Matemática, e percebesse que tem potencial para desenvolver atividades com diferentes conceitos matemáticos. Optamos pelo método geométrico, não oferecido pelo material didático, com o intuito de aproveitar as habilidades demonstradas pelo aluno.

Planejamos cinco sessões individuais e duas coletivas. Elas tiveram o propósito de que o aluno realizasse as mesmas atividades que eram disponibilizadas aos seus colegas durante as aulas.

\subsubsection{Ferramenta material de Equações do $2^{\circ}$ Grau}

Trata-se de um método visual, desenvolvido por escribas babilônicos durante a primeira metade do segundo milênio antes de Cristo, que conta com materiais manipulativos e que contribui para desenvolver o pensamento em um processo investigativo de resolução de problemas, combinando tanto a experiência numérica quanto a experiência geométrica. A ideia chave desse tipo de problema aparece na obra de Al-Jabr de Al-Khawarizmi, matemático muçulmano do século VIII d.C., que utilizava a técnica de completar quadrado para resolver equações quadráticas. Ele resolvia as equações de forma retórica, mas utilizava o método geométrico para justificar a exatidão de suas regras (RADFORD, 2011). 
Utilizamos o material ${ }^{5}$ adaptado por Fernandes (2012), confeccionado em E.V.A. no tamanho A4, em duas cores distintas - verde e branco (Figura 10).
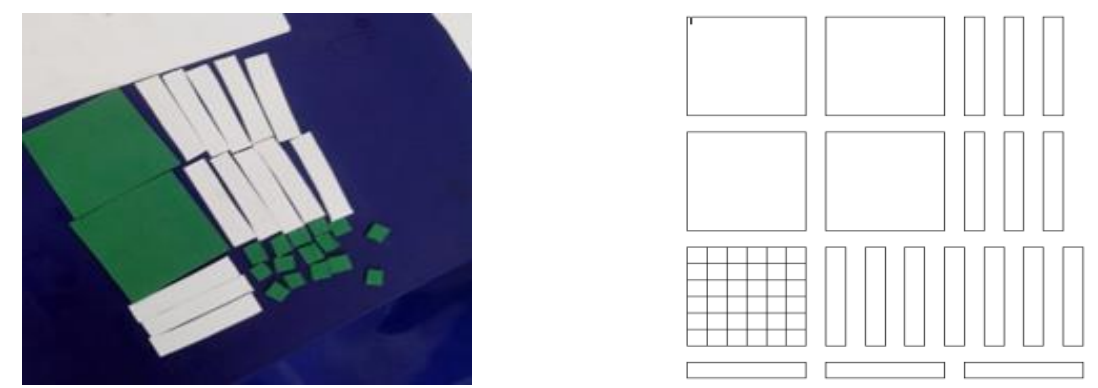

Figura 10 - Material para o estudo das Equações do $2^{\circ}$ grau em E.V.A.: $2 x^{2}-13 x+15$ Fonte: Arquivo do grupo de pesquisa (2014).

As figuras desenhadas em E.V.A. formam as peças de um jogo no qual o quadrado grande tem dimensões $\mathrm{x}$ e área $\mathrm{x}^{2}$, o retângulo tem lados x e 1 e área $\mathrm{x}$ e o quadrado pequeno tem dimensões 1 e área 1 . O primeiro passo é estabelecermos o significado de cada peça quadrado grande, retângulo e quadrado pequeno: as peças de cor verde representam, respectivamente, $x^{2}, x$ e 1 , com sinais positivos; ao passo que as peças de cor branca representam, respectivamente, $-\mathrm{x}^{2},-\mathrm{x}$ e -1 .

Um trinômio da forma $\mathrm{ax}^{2}+\mathrm{bx}+\mathrm{c}$ pode ser fatorado se uma forma retangular puder ser construída com as peças do material que o representam. As dimensões do retângulo formado são chamadas de fatores do trinômio.

\subsubsection{Resolvendo as equações do $2^{\circ}$ grau geometricamente}

A sessão iniciou-se com a apresentação do material para Caio. Ele escolheu verde para representar os valores positivos e branco para os negativos. Em seguida, a pesquisadora foi conduzindo a conversa com o aluno, para que ele conhecesse os valores de cada peça. A proposta consistia em Caio manusear o material e formar retângulos com as peças que compusessem a equação desejada.

Iniciamos com a expressão $x^{2}+3 x+2$, representada assim: $x^{2}$ : por um quadrado grande verde; $3 \mathrm{x}$ : por 3 retângulos verdes; e 2: por 2 quadrados pequenos verdes. O objetivo era formar um retângulo com essas seis peças. Formamos um retângulo de lados $\mathrm{x}+2 \mathrm{e} x+1$, assim $\mathrm{x}^{2}+3 \mathrm{x}+2$ $=(\mathrm{x}+2)(\mathrm{x}+1)$.

A segunda expressão proposta na atividade foi $x^{2}+6 x+5=0$. $O$ aluno demonstrou entusiasmo ao ter compreendido o método e gostado do material. Caio separou um quadrado

${ }^{5}$ Representação Geométrica da forma fatorada de equações do $2^{\circ}$ grau. 
maior verde, seis retângulos e cinco quadrados pequenos, todos de cor verde e, em seguida, montou um retângulo utilizando todas as peças. A expressão seguinte, proposta a Caio, foi $\mathrm{x}^{2}+6 \mathrm{x}+8$. O aluno, em silêncio, separou um quadrado grande verde, seis retângulos verdes e oito quadrados pequenos verdes e formou um retângulo com todas as peças.

Observando o aluno, pudemos perceber que ele tinha um procedimento próprio para fazer sua representação e que o seguia em todas as situações - primeiramente, separava as peças necessárias para a resolução da equação. Iniciava o processo sempre com o quadrado maior; em seguida, encaixava todos os retângulos na vertical, ao lado do quadrado e, por último, tentava completar o retângulo com os quadrados menores. Ao perceber que sobravam quadradinhos pequenos ou faltavam, ele reposicionava alguns retângulos na horizontal e encaixava um a um os quadrados menores, até conseguir.

A mediação da pesquisadora e dos materiais, nesse episódio, foi fundamental. $\mathrm{O}$ aluno compreendeu e realizou ações que, sozinho, não faria. Na visão de Vygotsky (1997), em relação aos "meninos dificilmente educáveis", todos os processos de desenvolvimento se convertem em processos mediados e são assimilados por meio de métodos, como uma forma de usar a operação psicológica.

$\mathrm{Na}$ sessão seguinte, as atividades propostas consistiam em formar, com as peças, um retângulo que representasse cada uma das equações; em seguida, escrever as dimensões do retângulo na coluna denominada "forma fatorada" e determinar as raízes da equação, anotando os valores no quadro. Por exemplo:

\begin{tabular}{|c|c|c|c|c|c|}
\hline Equações & Forma fatorada & $\begin{array}{c}\text { Raízes da equação } \\
\mathbf{x}^{2}+\mathbf{b x}+\mathbf{c}=\mathbf{0}\end{array}$ & $\mathbf{a}$ & $\mathbf{b}$ & $\mathbf{C}$ \\
\hline a) $\mathrm{x}^{2}+3 \mathrm{x}+2=0$ & $(\mathrm{x}+2)(\mathrm{x}+1)=0$ & $-2 \mathrm{e}-1$ & 1 & 3 & 2 \\
\hline b) $\mathrm{x}^{2}-2 \mathrm{x}+1=0$ & $(\mathrm{x}-1)(\mathrm{x}-1)=0$ & $-1 \mathrm{e}-1$ & 1 & -2 & 1 \\
\hline
\end{tabular}

Quadro 1 - Dimensões do retângulo

Fonte: Arquivo do grupo de pesquisa (2014).

Caio representou geometricamente algumas equações do segundo grau e facilmente compreendeu como encontrar os elementos $a, b$ e $c$ na equação de $2^{\circ}$ grau e também suas raízes. Conforme as equações eram apresentadas, o aluno aprimorava a técnica de montar os retângulos e encaixá-los rapidamente, tornando-se, a cada equação, mais autônomo no processo de resolução das equações.

Vejamos o procedimento utilizado para encontrar as raízes da equação $x^{2}+5 x+6=0$. Caio escutou atento às orientações da pesquisadora.

Pesquisadora: Então me diga quais peças você vai precisar e pode ir pegando.

Caio: $x^{2}$ é um quadrado grande verde, né? Mais cinco é cinco retângulos dos verdes mais seis quadradinhos verdes.

(Diálogo entre professor e aluno, 2014). 
Caio concentrado, em silêncio, foi montando o retângulo (Figura 11) e, sem pronunciar palavra alguma, preencheu a atividade completando com $(x+2)(x+3)=0$ a segunda coluna do quadro, com -2 e -3 as raízes, e escreveu os respectivos valores dos termos a, b e c.

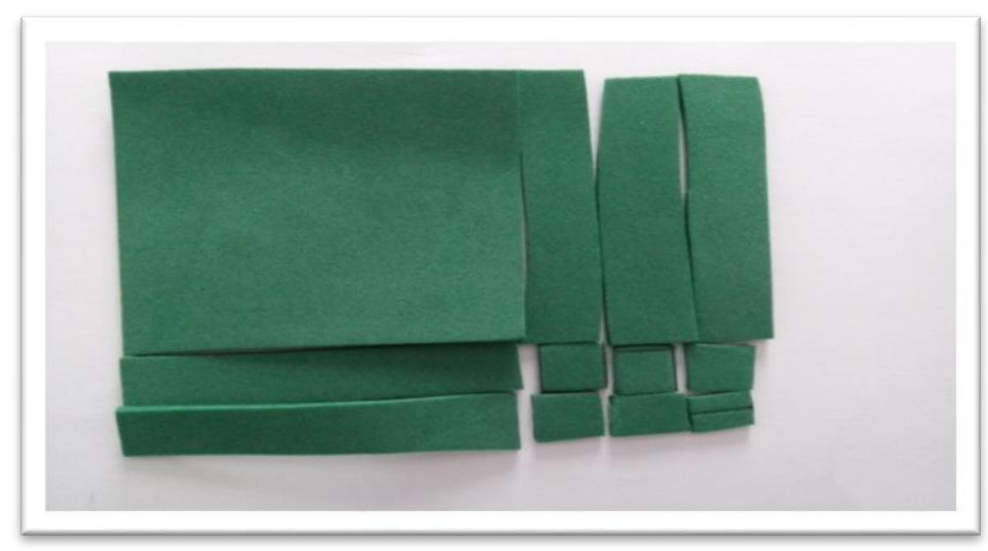

Figura 11 - Resolução da equação $x^{2}+5 x+6$

Fonte: Arquivo do grupo de pesquisa (2014).

A comunicação entre pesquisadora e aluno, na maioria das vezes, iniciava-se com um olhar. Ao surgir uma dúvida, ele parava e ficava olhando para ela, sem pronunciar palavra alguma. Somente depois que a pesquisadora o questionava é que ele se pronunciava.

O aluno ficava ansioso e pouco confortável toda vez que era submetido a alguma nova situação. Verificamos, em nosso estudo, conforme o que apresenta Smith (2008), que a rotina e as ações previsíveis são boas aliadas para se trabalhar com pessoas com o TEA. Pensando nisso, organizamos uma atividade para ser realizada com a turma de Caio, empregando o material utilizado por ele nas sessões individuais. Tal procedimento consistiu em planejarmos um cenário inclusivo para a aprendizagem matemática.

\subsubsection{Aulas em dupla com o material}

A pesquisadora organizou a classe com 28 alunos em duplas. Cada dupla recebeu duas folhas A4 para pintarem com duas cores de preferência e estabelecerem a cor positiva e a negativa. Elaboramos uma atividade, similar à realizada por Caio no atendimento individual, contendo Equações do $2^{\circ}$ grau, que os alunos deveriam resolver geometricamente - com o auxílio do material - explicitar os termos $a, b$ e $c$ da equação, as raízes e, por fim, responder algumas questões que os levariam a relacionar os termos à soma e ao produto das raízes da equação. Caio participou efetivamente da aula, realizou a atividade e ensinou a colega, com quem fez dupla, a resolver algumas equações que ela não conseguiu fazer sozinha (Figura 12). 


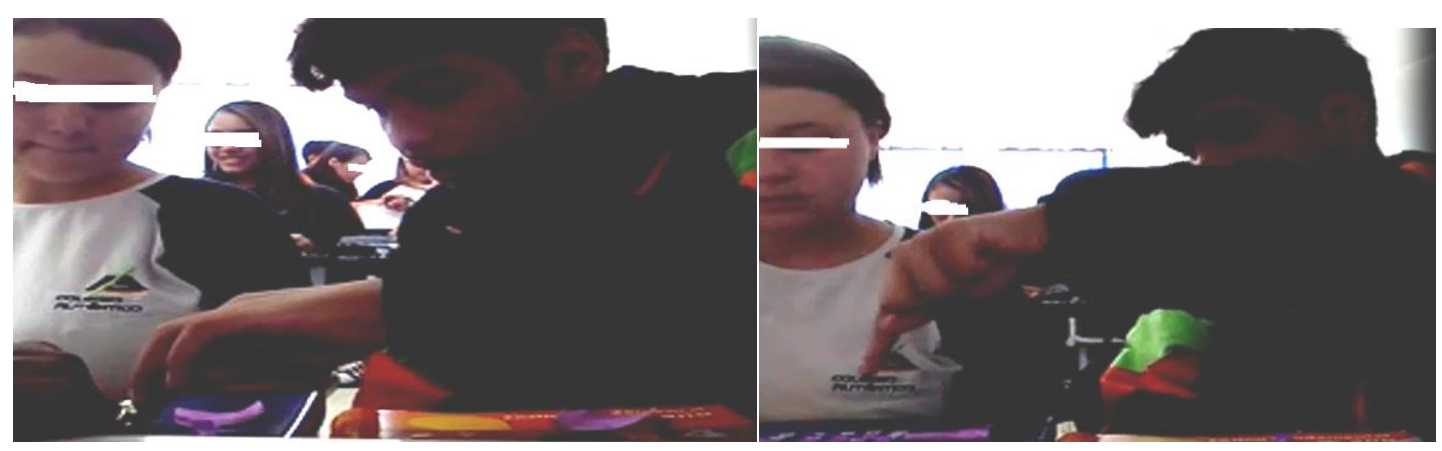

Figura 12 - Atividade em dupla na sala de aula Fonte: Arquivo do grupo de pesquisa (2014).

No momento em que os colegas das duplas próximas perceberam que Caio dominava o assunto, começaram a pedir auxílio para a resolução de algumas equações. De acordo com a maneira peculiar de Caio se comunicar, que conta mais com gestos do que palavras, nesse episódio, ele gesticulava e apontava para as figuras, fazendo movimentos com as mãos, movendo as peças e repetindo a equação, de acordo com o nome da peça.

Nesse sentido, sob a perspectiva de Vygotsky, o sujeito começava a perceber o mundo nas experiências sociais, o que era demonstrado por meio dos olhos, dos gestos e da fala. De acordo com o autor, até nos estágios mais precoces do desenvolvimento, a linguagem está relacionada com a percepção humana ${ }^{6}$. Por exemplo, um problema, mesmo que resolvido sem a emissão de som, apresentava a importância da linguagem no resultado, pois o imediatismo da percepção natural era mediado por meio da fala, parte essencial no desenvolvimento cognitivo da criança, que ajudava no desenvolvimento da consciência (VEER; VALSINER, 1996).

Ao auxiliar a dupla que estava atrás e não conseguia iniciar o procedimento para resolução da equação $x^{2}+2 x+1$, Caio deixou sua colega de dupla realizando o exercício e focou toda a atenção para a outra dupla que solicitara sua ajuda, dizendo:

Caio: Xis quadrado é o quadrado (sussurrando com a cabeça baixa).

Colega: Eu não sabia que xis quadrado era o quadrado.

Caio: Agora você coloca mais dois xis (apontando para os retângulos).

Colega: Coloquei.

Caio: Mais um (apontando para os quadrados pequenos) (Gravação de vídeo, 13/10/14).

A colega que estava realizando a atividade com Caio, a princípio, não contava muito com a ajuda do garoto e preferia perguntar as dúvidas para a professora. Porém, no decorrer do processo, ela percebeu que ele realmente sabia usar o material e resolver as situações propostas. Ao final do primeiro dia da atividade, alguns colegas sentados mais próximos de Caio estavam

\footnotetext{
${ }^{6} \mathrm{O}$ mundo não é visto simplesmente em cor e forma, mas também como um mundo com sentido e significado. Toda percepção humana consiste em percepções categorizadas, ao invés de isoladas (VYGOTSKY, 1998a, p. $50)$.
} 
impressionados e faziam comentários, como, por exemplo:

Colega A: Nossa até que ele é muito esperto!

Colega B: Acho que é nesse negócio que ele é esperto.

Colega C: Cada um tem uma coisa em que é esperto!

Companheira de dupla: Nossa, o Caio é muito esperto, teve um negócio lá que eu não consegui resolver, ai ele foi lá e fez; me ensinou e eu aprendi! (Gravação de vídeo, 13/10/14).

Para Vygotsky, o uso de instrumentos e signos desenvolve formas e funções psicológicas novas, que, segundo o autor, possibilitam o desenvolvimento das habilidades relacionadas ao controle e à direção do próprio comportamento (VYGOTSKY, 1998a). Com esse olhar, percebemos que a interação entre colegas, as intervenções da pesquisadora e o uso do material trouxeram possibilidades cognitivas e contribuíram nos aspectos educacionais e sociais. Todos os envolvidos participaram do processo como aprendizes e instrutores. Ao final da aula, a garota comentou com outros colegas da classe:

Vocês não têm noção de como o Caio é esperto! Ele sabe resolver tudo desses negócios! (Gravação de vídeo, 13/10/14).

Ao realizarmos com a classe a mesma atividade, que apresentava uma nova maneira de calcular uma equação do $2^{\circ}$ grau, todos os envolvidos ganharam com essa experiência. Além do aprendizado do conteúdo matemático, Caio ficou muito seguro de si, feliz e entusiasmado, chegando a perguntar o que aprenderia no próximo atendimento.

Com o passar das aulas, retomamos o assunto e Caio não precisava mais do material concreto para resolver as equações. Ele desenvolveu uma estratégia para lidar com esse conteúdo matemático, representando geometricamente por meio de desenhos a equação do $2^{\circ}$ grau proposta. Analisando essa ação, na perspectiva de Vygotsky (1997), notamos que aquela ferramenta, que era material, passou a ser uma ferramenta psicológica, e pudemos perceber que o instrumento se transformou em um signo.

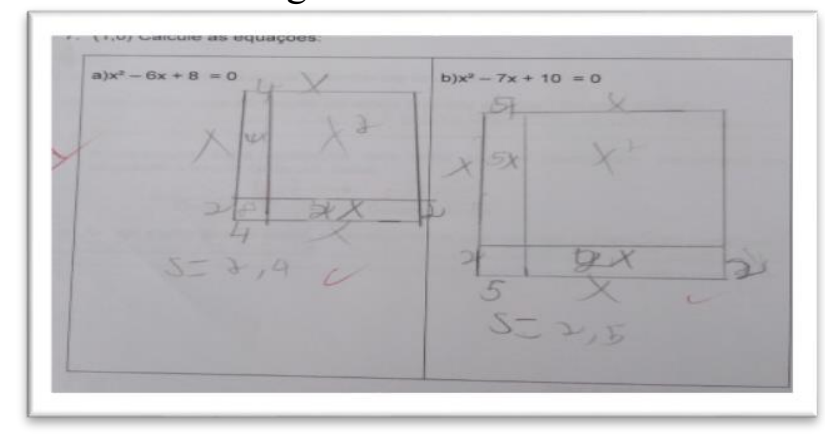

Figura 13 - Avaliação de Caio sem o Material Fonte: Arquivo do grupo de pesquisa (2014).

Em todo o estudo, buscamos desenvolver caminhos não convencionais com o aluno com autismo, sempre mediando as atividades por meio da fala e de objetos. Pudemos perceber que Caio, a partir do momento em que teve a possibilidade de acessar representações dos objetos 
matemáticos em estudo que tinham significado para ele e por meio de instrumentos que ele podia controlar, passou a participar ativamente das aulas de Matemática.

Segundo o documento Saberes e Práticas da Inclusão (BRASIL, 2003), o professor pode se impressionar com a capacidade de aprender do aluno com autismo quando a forma de ensino adotada for adequada para ele. Em nosso estudo, Caio surpreendeu a pesquisadora diversas vezes, com seu raciocínio e sua forma peculiar de construir o raciocínio algébrico.

O documento destaca, ainda, que a comunicação verbal é um dos problemas do aluno com autismo e, em nossa pesquisa, constatamos esse fato durante as sessões individuais, nas quais a maior parte da comunicação deu-se por meio de olhares e gestos. O documento também aponta que o efeito positivo dos outros alunos e das outras pessoas sobre o aluno com autismo só vai surgir depois que esse aluno começar a adquirir a consciência de si mesmo, ocorrendo conforme o avanço do desenvolvimento cognitivo.

Em nosso estudo, esta ação se concretizou a partir do momento em que Caio conseguiu ensinar os colegas e mostrar que também era capaz. O garoto começou a tirar boas notas em Matemática e nas outras disciplinas, melhorou sua autoestima e até os aspectos físicos mudaram.

\section{Considerações finais}

No período das sessões mencionadas, algumas mudanças visíveis puderam ser percebidas. Caio desenvolveu a autoestima, começou a se arrumar e a cuidar mais da aparência, a participar das aulas, a pedir o auxílio da professora para a resolução de exercícios que queria fazer na lousa e, segundo sua mãe, ele passou a gostar de frequentar a escola no contraturno.

Apresentamos algumas situações de aprendizagem matemática de Caio, realizadas no ambiente escolar, envolvendo Produtos Notáveis e as Equações do $2^{\circ}$ grau, com o intuito de avaliar o potencial de diferentes práticas e materiais - elementos mediadores - que permitiram o acesso do aprendiz a conteúdos matemáticos e contribuíram para que ele pudesse acompanhar as aulas de Matemática juntamente com seus pares. As práticas adotadas neste artigo, juntamente com os materiais e a pesquisadora, tornaram o processo mais seguro e acessível a Caio e possibilitaram a emergência de suas habilidades que, antes, não eram percebidas.

O planejamento deste estudo partiu do princípio de que o aluno poderia desenvolver-se e avançar para, posteriormente, tornar-se independente em suas práticas escolares. Traçamos ações que respeitaram as peculiaridades do aprendiz, de modo a que dessem acesso aos conhecimentos matemáticos. Para tanto, contamos com a prática da mediação com ferramenta 
material e semiótica.

Ao inserirmos os alunos em um cenário inclusivo para a aprendizagem matemática, todos os envolvidos ganharam com a experiência. Além do aprendizado do conteúdo matemático, para o qual a maioria demonstrou entendimento, foi uma experiência enriquecedora para todos, que, apesar de sempre respeitarem as dificuldades de Caio, não acreditavam que ele seria capaz de aprender ou ensinar algo. Caio, ficou muito seguro de si, feliz e entusiasmado. Em poucas palavras, relatou ter gostado de fazer a atividade em sala, disse que gostou de tudo o que os amigos disseram a seu respeito e que gostaria de mais aulas assim. Ele sentiu-se parte do grupo - incluído.

Parafraseando Ainscow (2016, p. 147), temos que "a inclusão é um processo [...] precisamos aprender a viver com a diferença, e, aprender a aprender com a diferença”". Consideramos que as escolas inclusivas são aquelas que percebem a diversidade como um fator de enriquecimento do ser humano e do processo educacional. A inclusão identifica e remove barreiras e usa as "evidências [...] para estimular a criatividade e a resolução de problemas" (FERNANDES, 2017). A proposta das escolas inclusivas deve ser oferecer a todos os alunos meios que favoreçam a superação de suas limitações, tornando-os participantes ativos de um sistema educacional equitativo. "Inclusão é sobre a presença, participação e realização de todos os alunos" (FERNANDES, 2017). Ao considerarmos temas relacionados à inclusão, não é o bastante ter todos os alunos compartilhando o mesmo ambiente escolar. É preciso criar mecanismos que nos permitam modificar as estruturas educacionais (currículos e avaliações, por exemplo) e alguns ambientes escolares que temos hoje, ambos baseados na classificação, na segregação e na exclusão.

\section{Referências}

AINSCOW, M. Diversity and Equity: A Global Education Challenge. New Zealand Journal of Educational Studies, Nova Zelândia, v. 51, n. 2, p. 143-155, 2016. DOI: 10.1007/s40841-016-0056-x NZJES

ASPERGER, H. Autistic psychopathy in childhood. In: FRITH, U. (Ed.). Autism and Asperger syndrome. Londres: Cambridge University Press, 1991. p. 37-92. (Trabalho original publicado em 1944).

BOSA, C. A.; CAMARGO, S. P. H. Competência Social, Inclusão Escolar e Autismo: Revisão Crítica de Literatura. Psicologia \& Sociedade. Scientific Electronic Library Online - SciELO, Florianópolis, v. 21, n. 1, p. 65-74, jan/abr. 2008. Disponível em: <http://www.scielo.br/pdf/psoc/v21n1/08.pdf.>. Acesso em: 29 out. 2017.

BRASIL, Secretaria de Educação Especial. Saberes e Práticas da inclusão: dificuldades acentuadas de aprendizagem: autismo. 2. ed. SEESP/ MEC - Brasília: MEC, 2003. 64p. Disponível em: $<$ http://portal.mec.gov.br/seesp/arquivos/pdf/educacao\%20infantil\%203.pdf $\geq$. Acesso em: 27 de out. 
2017.

FERNANDES, S. H. A. A. Resolução de Equações do $2^{\circ}$ grau. São Paulo. Universidade Anhanguera de São Paulo, 2012. (Apostila Não Publicada).

FERNANDES, S. H. A. A.; HEALY, L. Design para A Diversidade: Matemática Escolar E Inclusão. In: V CONGRESSO INTERNACIONAL DA PRÓ-INCLUSÃO, 5., 2017, Lisboa. Anais ... Lisboa, 2017. p. s.n.

KANNER, L. Autistic disturbances of affective contact. Nervous Child, Baltimore, v. 2, p. 217-250, 1943. Disponível em: <http://neurodiversity.com/library_kanner_1943.pdf>. Acesso em 29 out. 2017.

OLIVEIRA, M. K. de. Vygotsky: Aprendizado e desenvolvimento: um processo sócio-histórico. São Paulo: Scipione, 2009.

RADFORD, L. Cognição Matemática: História, Antropologia e Epistemologia. São Paulo: Editora Livraria da Física, 2011.

SACKS, O. Um antropólogo em Marte: sete histórias paradoxais. Tradução de: Bernardo Carvalho. 4. ed. São Paulo: Companhia das Letras, 2006.

SILVA, A. B. B.; GAIATO, M. B.; REVELES, L. T. Mundo singular: entenda o autismo. Rio de Janeiro: Objetiva, 2012.

SMITH, D. D. Introdução à Educação Especial: ensinar em tempos de inclusão. 5. ed. Porto Alegre: Artmed, 2008.

VEER, R.; Van, D.; VALSINER, J. Vygotsky - Uma síntese. Tradução de: Cecília C. Bartalotti. 4. ed. São Paulo: Loyola, 1996.

VYGOTSKY, L. S. Obras escogidas V. Fundamentos da defectología. Traducción: Julio Guillermo Blank. Madrid: Visor, 1997.

VYGOTSKY, L. S. A formação social da mente. Tradução José Cipolla Neto, Luís Silveira Menna Barreto, Solange Castro Afeche. 6. Ed. São Paulo: Martins Fontes, 1998a. (originalmente publicado em russo, em 1930).

VYGOTSKY, L. S. Pensamento e linguagem. Tradução Jefferson Luiz Camargo. 2. ed. São Paulo: Martins Fontes, 1998b. (originalmente publicado em russo, em 1934).

VIGINHESKI, L. V. M. Uma Abordagem para o Ensino de Produtos Notáveis em uma classe inclusiva: o caso de uma aluna com deficiência visual. 2013. 156f. Dissertação (Mestrado em Ensino em Ciência e Tecnologia) - Universidade Tecnológica Federal do Paraná, Campus de Ponta Grossa, Paraná. Área de concentração: Ensino de Matemática, 2013. Aprovado em 30 de Abril de 2018. 